\title{
Comparison of Coordinative Abilities of Child Wrestlers and Judokas
}

\author{
Yaşar Çoruh ${ }^{1}$, Serkan Zengin ${ }^{1}$ \\ ${ }^{1}$ Ağrı İbrahim Çeçen University, School of Physical Education and Sports, Department of Physical Education and \\ Sports Management, Ağr1, Turkey \\ Correspondence: Yaşar Çoruh, Ağrı İbrahim Çeçen University, School of Physical Education and Sports, Department of \\ Physical Education and Sports Management, Ağr1, Turkey. E-mail: ycoruh@agri.edu.tr
}

\author{
Received: May 28, 2019 \\ Accepted: June 19, 2019 Online Published: June 20, 2019 \\ doi:10.11114/jets.v7i9.4334 \\ URL: https://doi.org/10.11114/jets.v7i9.4334
}

\begin{abstract}
The aim of this research is to compare the coordinative abilities of child wrestlers and judokas. Totally 52 athletes were included into the research by taking consent from their families; 26 judoka children whose age average is $13.45 \pm 0.506$ years, height average is $1.52 \pm 0.090 \mathrm{mt}$ and body weight average is $47.52 \pm 13.193 \mathrm{~kg}$ and 26 judoka whose age average is $14.75 \pm 0.639$ years, height average is $1.59 \pm 0.064 \mathrm{mt}$ and body weight average is $49.85 \pm 8.786 \mathrm{~kg}$. All risks and benefits pertaining to the research were explained to the parents of athletes and they were asked to sign the university confirmed voluntary permission form. Numbered medicine ball running test, Backward Medicine Ball Throw Test and sprint test to the given rhythm were used for the purpose for determining the orientation, differentiation and rhythm performances in regard to coordinative abilities of the individuals participating into the research. SPSS 22 program was used for the analysis of the data obtained. It was found out according to the result of One Sample Kolmogorov-Smirnov test performed that data related with rhythm times exhibited normal distribution, data related with orientation times and differentiation scores did not exhibit normal distribution. For this reason, while Independent Samples T test was used in comparison of data related with rhythm times by the type of sports, Mann Whitney U test was used in comparison of data related with orientation times and differentiation scores by the type of sports. Once the results related with research were examined, while it was seen that the rhythm times and orientation times of wrestlers were significantly better than those of judoka, it was concluded that any significant difference was not available for the differentiation ability.

In conclusion, the findings of the study do not confirm our pre-research expectations. Once the related literature is examined, it is seen that there are many various results related with the coordinative abilities pertaining to different sports branches.
\end{abstract}

Keywords: coordinative abilities, wrestlers, judokas, differentiation, orientation, rhythm

\section{Introduction}

Motor coordination is defined as the ability of displaying the motions containing skill in a fast, fluent and successful way (Connick et al. 2015; Runciman and Derman, 2018).

Coordinative abilities are known as skill, competence and mastery defined by the body motion control and orientation process. The skill Word used by many authors in the literature has a more restrictive meaning compared with wealth (complexity) which defines the distinctive indications of these abilities. The same authors define the coordinative abilities as follows. It is a psychometric qualities' mixture that is unique to the activities in various types by restructuring the physical basis that principally exists, orients itself to the different situations in a fast and efficient way, implies the ability of learning new motions quickly (Smidu, 2014).

Judo is a sport that entails the complex motions to be performed and high-level planning to be used. It is seen that there are differences in the regional brain morphology of judoka and athletes of other defense arts compared with sedentary individuals (Jacini et al., 2008, Schlaffke et al, 2014). In other words, judo is a dynamic sport which contains high-density intervals requiring complex skills and tactical excellence for the success. Judoka must perform many actions during the match (Degoutte et al., 2003, Van malderen et al., 2006).

Wrestling is an intermittent sports type in which both upper and lower body demands great force and high muscle strength and which needs a high anaerobic energy metabolism (Horswill et al., 1989; Horswill 1992; Kraemer et al., 2001; Wozniak et al., 2004). When Pallares et al. (2011) examined the literature, they stated that although aerobic 
performance is an essential requirement for the wrestlers, many researchers reported that it cannot be considered as a serious component for the success in the wrestling.

Being successful in many modern sports is associated with the abilities of running, jumping, pushing, pulling and throwing. Mobility is a biological need for every individual, however, performance-based motions in terms of quality are necessary for the success and high-level performance in the sports. Sports are the activities containing complex motions in it and it is based on performance of various motions. Therefore, different sports branches need different coordinative abilities (Singh, 2004).

Once the literature is examined, it is seen that there are studies carried out for the examination of the relation between the agility performance and some coordinative abilities of judoka, searching of the relation between the match ability and some coordinative abilities of wrestlers and judoka (Rana and Rajpoot 2015; Peker et al., 2017; Taşkın et al., 2017). However, it was seen that there was no study conducted for the purpose of determining the coordinative abilities of these two sports branches for comparing the coordinative abilities of judoka and wrestlers. Hence, the aim of this research is to compare the coordinative abilities of child wrestlers and judokas. Once the characteristic features of judo and wrestling sports are considered; our pre-research expectation is that judoka may have more developed coordinative abilities compared to wrestlers.

\section{Method}

\section{Participants}

Totally 52 athletes were included into the research by taking consent from their families; 26 judoka children whose age average is $13.45 \pm 0.506$ years, height average is $1.52 \pm 0.090 \mathrm{mt}$ and body weight average is $47.52 \pm 13.193 \mathrm{~kg}$ and 26 wrestler children whose age average is $14.75 \pm 0.639$ years, height average is $1.59 \pm 0.064 \mathrm{mt}$ and body weight average is $49.85 \pm 8.786 \mathrm{~kg}$. All risks and benefits pertaining to the research were explained to the parents of athletes and they were asked to sign the university confirmed voluntary permission form.

\section{Measurements}

Numbered medicine ball running test, backward medicine ball throw test and sprint test to the given rhythm were used for the purpose for determining the orientation, differentiation and rhythm performances in regard to coordinative abilities of the individuals participating into the research. Test-retest intraclass reliabilities for these tests were consecutively, .92, .95, .93 (Sing 2004).

\section{Numbered medicine ball running test}

This test is used for measuring the orientation ability. As shown in Figure 1, five medicine balls, each of which is $3 \mathrm{~kg}$ and one medicine ball weighting $4 \mathrm{~kg}$ were placed onto the ground. The medicine balls were positioned in such a way which will create a shape resembling a pentagon. While $4 \mathrm{~kg}$ of medicine ball was located at the center of ground edge of the shape, $3 \mathrm{~kg}$ of medicine balls were positioned around the $4 \mathrm{~kg}$ of medicine ball. It was arranged in such a way in which distance between each of $3 \mathrm{~kg}$ of medicine balls would be 1,5 meters, the distance between the $4 \mathrm{~kg}$ of medicine ball located at the center of the ground edge of the shape would be 3 meters. Prior to starting test, it was said to test subjects to stand on the opposite directions in a facing back position behind the photocell positioned just behind totally 6 medicine balls. The subject started test returned from the position he/she stood with the signal, he/she started test by passing through the photocell, he/she firstly touched the $4 \mathrm{~kg}$ of medicine ball and he/she was directed by the test practitioner to one of the $2 \mathrm{~kg}$ of medicine balls by saying the number of ball at this moment. The subject touched the ball whose number was said and run to the part where $4 \mathrm{~kg}$ of medicine ball was located and stood in a facing back position, however, he/she did not cause the photocell to stop by passing through it. The test practitioner started test for the second time without allowing the subject to wait and after he/she make his/her return again, he/she firstly touched the $4 \mathrm{~kg}$ of ball and then, he/she was directed to one of the numbered balls by the test practitioner. This procedure was repeated for 3 successive times and the subject who came to the part where the $4 \mathrm{~kg}$ of medicine ball was located in the center completed the test by passing through the photocell in the last repetition. Each subject performed 1 trial and then, test was applied. Time when the subject completed the test was recorded as second. Test was applied to subjects for 2 times and the best rating was obtained (Chib 2000;Minz 2003; Singh 2004). 


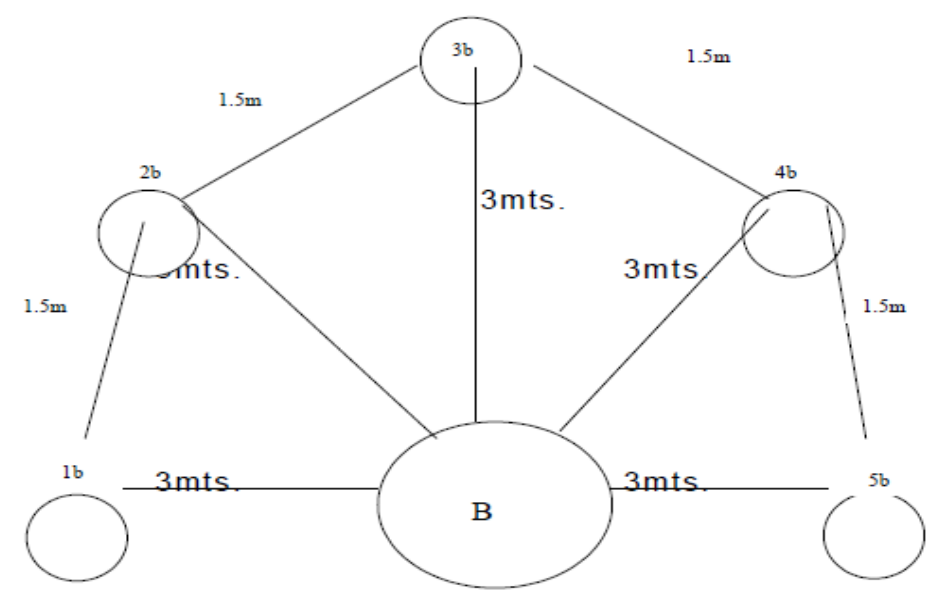

$$
\begin{aligned}
& \mathrm{B}-\text { Medicine Ball Weighing } 4 \mathrm{Kg} \text {. } \\
& \mathrm{b}-\text { Medicine Ball Weighing } 3 \mathrm{Kg} \text {. }
\end{aligned}
$$

Figure 1. Numbered medicine ball running test

\section{Backward Medicine Ball Throw Test}

This test is used for measuring the differentiation ability. A gymnastic matte in length of three meters and in width of 6 meters was positioned 1,5 meters away from the starting line, as seen in Figure 2. A circle in diameter of $40 \mathrm{~cm}$ was drawn in the middle of matte and $2 \mathrm{~kg}$ of medicine ball was placed into this circle. It was said to the subjects to wait behind the starting line in such a way which will face to the opposite direction. It was asked from the subjects to try to strike the medicine ball within the circle by launching a $1 \mathrm{~kg}$ medicine ball with two hands over the head without looking back. The subjects repeated the test for 2 times after 1 trial and the best rating was accepted as the score.

The scoring was performed as follows;

1 score when the medicine ball launched by the subjects touches the matte

2 scores when the medicine ball launched by the subjects touches the line of circle

3 scores when the medicine ball launched by the subjects falls into the circle

4 scores when the medicine ball launched by the subjects strikes another medicine ball within the circle.

Total of all scores obtained by launching 5 balls created the individual score (Chib 2000; Minz 2003; Singh 2004).

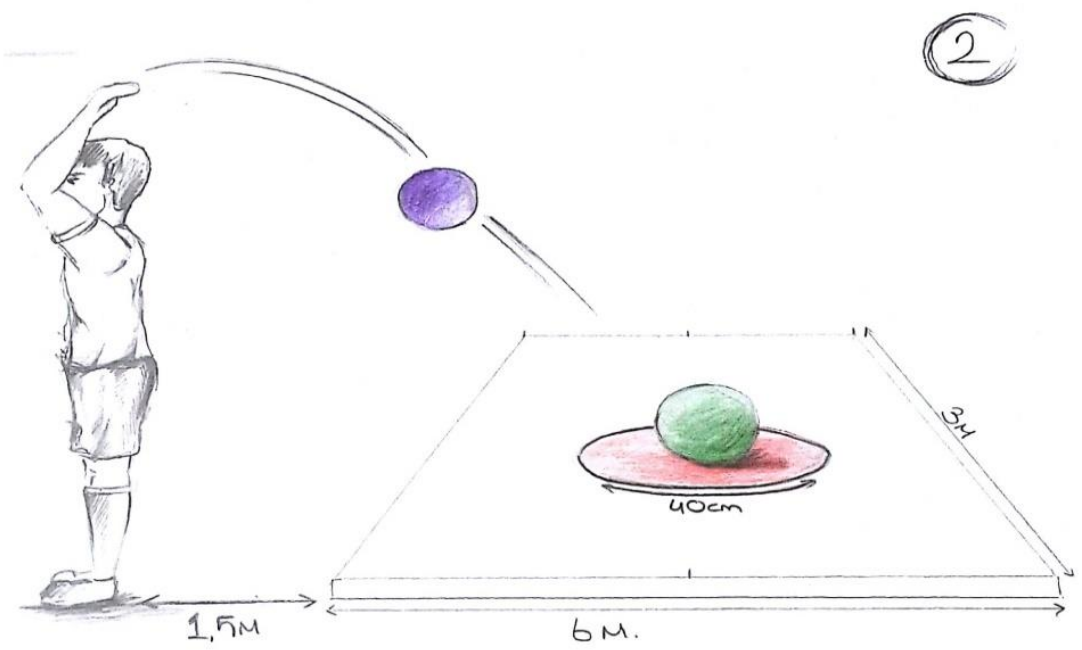

Figure 2. Backward Medicine Ball Throw Test 


\section{Sprint test to given rhythm}

This test is used for measuring the rhythm ability. 11 gymnastic hoops were positioned systematically, as is seen in Figure 3. The first 3 hoops were aligned in a consecutive order in an adjacent way with each other 5 meters away from the starting line. Similarly, the other 3 hoops were positioned 5 meters away from the finishing line. The remaining 5 hoops were positioned in an adjacent line with each other in the middle of the running distance. The distance between the starting line and finishing line is 30 meters. Also, two photocells were placed in starting and finishing points of the 30 meters of line for determining the running time. Test was shown and explained to the subjects before implementing the test. Then, the subjects run the 30 meters of distance in a straight way being independent from the gymnastic hoops as swift as possible. Afterwards, the subjects run by making stepping between each hoop by adjusting the rhythm throughout the 11 gymnastic hoops aligned systematically in a regular rhythm and at maximum speed. Each subject firstly made a trial. Then, the subjects run for 30 meters in a normal way for two times and for 30 meters in a rhythmic way for 2 times. The best rating was obtained for each running. Difference between the first and second running was recorded as rhythm score (Chib 2000; Minz 2003; Singh 2004).

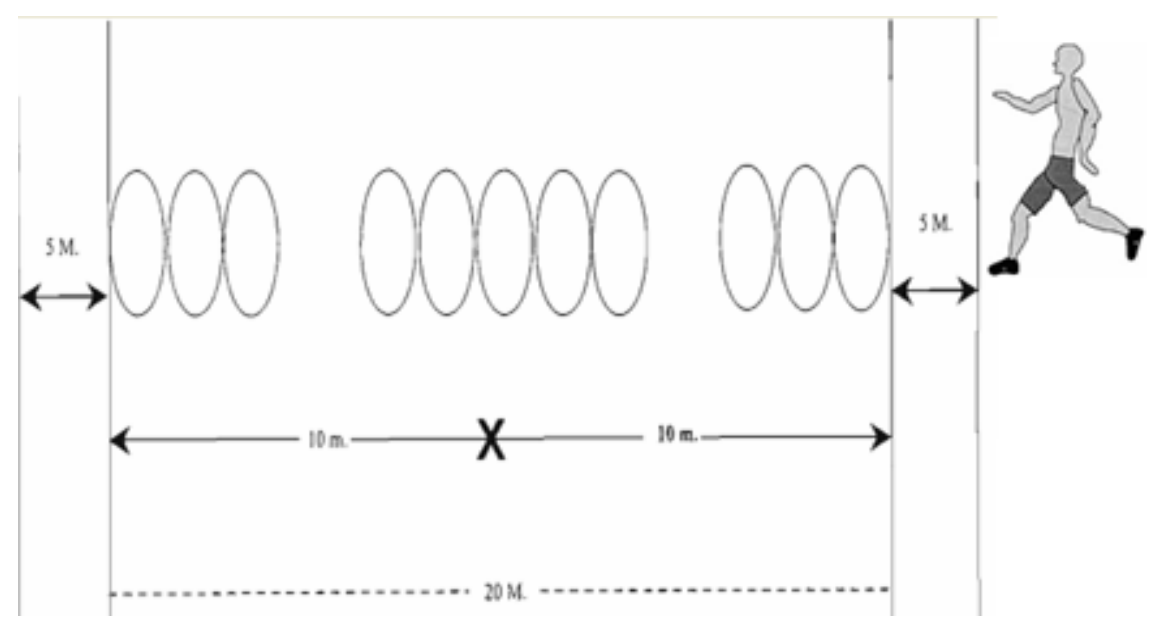

Figure 3. Sprint test to given rhythm

\section{Data Analysis}

Data obtained were analyzed in the SPSS 22 program. While data related with rhythm times of the participants exhibited normal distribution, data related with orientation times and differentiation scores did not exhibit normal distribution. Independent Samples $\mathrm{T}$ test was used for comparing the data related with rhythm times by the type of sports. Mann Whitney U test was used in comparison of data related with orientation times and differentiation scores by the type of sports. $\mathrm{P}<0.05$ was accepted as the significance level.

Table 1. Frequency and Percentage Distribution of Participants doing Wrestling and Judo

\begin{tabular}{ccc}
\hline Type of sports & F & \% \\
\hline Wrestling & 26 & 50 \\
\hline Judo & 26 & 50 \\
\hline Total & 52 & 100 \\
\hline
\end{tabular}

When the table is examined, it is seen that $50 \%$ of the participants do wrestling sports, $50 \%$ do judo sports.

Table 2. Descriptive Statistics pertaining to Age, Height and Body Weight of Participants doing Wrestling and Judo

\begin{tabular}{ccccc}
\hline \multirow{2}{*}{ Variables } & \multicolumn{2}{c}{ Wrestling } & \multicolumn{3}{c}{ Judo } \\
\cline { 2 - 5 } & $\mathbf{X}$ & $\mathbf{S s}$ & $\mathbf{X}$ & $\mathbf{S s}$ \\
\hline Age & 13,45 & 0,506 & 14,75 & 0,639 \\
\hline Height & 1,52 & 0,090 & 1,59 & 0,064 \\
\hline Body weight & 47,52 & 13,193 & 49,85 & 8,786 \\
\hline
\end{tabular}

When the table is examined, mean age of the participants doing wrestling sports is $13,45 \pm 0,506$ years, mean height is $1,52 \pm 0,090 \mathrm{~m}$, mean body weight is $47,52 \pm 13,193 \mathrm{~kg}$; mean age of the participants doing judo sports is $14,75 \pm 0,639$ years, mean height is $1,59 \pm 0,64 \mathrm{~m}$ and mean body weight is $49,85 \pm 8,768 \mathrm{~kg}$. 
Table 3. Comparison of Rhythm Times of Participants doing Wrestling and Judo

\begin{tabular}{|c|c|c|c|c|c|}
\hline Type of Sports & $\mathbf{N}$ & $\mathbf{X}$ & Ss & $\mathbf{T}$ & $\mathbf{P}$ \\
\hline Wrestling & 26 & 1,15 & 0,444 & \multirow{2}{*}{$-2,699$} & \multirow{2}{*}{$0,010^{*}$} \\
\hline Judo & 26 & 1,52 & 0,518 & & \\
\hline
\end{tabular}

Rhythm times of the participants doing wrestling sports are better than those of the participants doing judo sports. The rhythm times of the participants differ at a statistically significant level by the type of the sports they do $(\mathrm{p}<0,05)$.

Table 4. Comparison of Orientation Times of Participants doing Wrestling and Judo

\begin{tabular}{cccccccc}
\hline Type of Sports & $\mathbf{N}$ & $\mathbf{X}$ & $\mathbf{S s}$ & Rank Average & Rank Total & $\mathbf{U}$ & P \\
\cline { 1 - 6 } Wrestling & 26 & 7,34 & 0,753 & 16,13 & 500,0 & \multirow{2}{*}{184,0} & $0,000^{*}$ \\
\hline Judo & 26 & 11,61 & 1,526 & 41,30 & 826,0 & & \\
\hline
\end{tabular}

Orientation times of the participants doing wrestling sports are better than those of the participants doing judo sports. The orientation times of the participants differ at a statistically significant level by the type of the sports they do $(\mathrm{p}<0,05)$.

Table 5. Comparison of Differentiation Scores of Participants doing Wrestling and Judo

\begin{tabular}{cccccccc}
\hline Type of sports & $\mathbf{N}$ & $\mathbf{X}$ & $\mathbf{S s}$ & Rank Average & Rank Total & U & P \\
\cline { 1 - 5 } Wrestling & 26 & 8,84 & 2,806 & 27,47 & 851,5 & \multirow{2}{*}{264,5} & 0,376 \\
\cline { 1 - 5 } Judo & 26 & 8,00 & 2,340 & 23,73 & 474,5 & & \\
\hline
\end{tabular}

Differentiation scores of the participants doing wrestling sports are better than those of the participants doing judo sports. However, the differentiation scores of the participants do not differ at a statistically significant level by the type of the sports they do $(\mathrm{p}>0,05)$.

\section{Discussion}

When the results of the research are examined, it is seen that means of rhythm and orientation abilities of the wrestler children are better in a statistically significant manner than those of judoka children. On the other hand, while it is determined that the differentiation ability scores of the wrestler children are higher than the differentiation ability scores of the judoka children, it is concluded that this difference is not statistically significant.

The rhythm ability enables the athletes to perceive a rhythm coming from the outer world and to reveal it during a motion action. In addition to this, athletes can reveal any rhythm existing in the motor memory again thanks to the rhythm ability (Minz, 2003).

Orientation is defined as the ability of designating the changing motion and position of the body at a time and location in regard to the motion to be performed. In other words, the position of the whole body or any part of the body is able to determine the location of the rival and teammates, ball and playing field by the gravitational force (Holmann and Hettinger, 1980).

Differentiation grounds over a voluntary and net difference existed between the field and time variables into which the motion process of the athlete that exists in the mind penetrates. The differentiation ability enables the athletes to perceive the finest details about the direction, time, spatial dimension and dynamism related with the motion during the realization of the motion (Minz, 2003).

It is seen that judo sports is a branch that needs skill at high level. Development of analytical functions, fast perception of ever-changing situations under the circumstances of match and mobility are the characteristics that judoka is expected to bear. Also, decisions which judoka take in complex situations are related with the qualities of the perception of stimulus coming from the external environment. Quick thinking and interpretation are components which assists athletes to prevent their rivals from presenting a tactical quality behavior or to be successful. It is considered that wrestlers generally need developed upper and lower extremity force and well-trained aerobic and anaerobic metabolism, and development of motor components such as agility, readiness and flexibility. Although our pre-study expectations are that judoka may have more developed coordinative abilities as a result of general characteristics pertaining to these two branches, the results of the study do not confirm our expectations.

In a study in which relation between the agility and orientation ability of judoka was examined, means of the orientation ability of 67 child judoka whose age mean was $10.34 \pm 1.40$ years were determined as $11.09 \pm 1.04$ seconds (Taşkın et al., 2017). 
20 karate player children whose age mean was $14.60 \pm 0.82$ years were included into a study conducted by Peker and Vural, (2018). According to the results of the research, orientation ability means were found as $11.69 \pm 1.61$ seconds, rhythm ability means were found as $1.82 \pm 0.64$ seconds.

In a study carried out for the purpose of examining the relation between basketball ability and coordinative abilities, orientation ability means of the adult basketball players were found as $7.9 \pm 0.57$ seconds, rhythm ability means as $0.87 \pm 0.14$ seconds and differentiation ability means as $10.7 \pm 3.19$ scores (Singh and Saini, 2017).

In another research conducted over volleyball players and handball players whose age ranges between 15-22, the orientation ability means of volleyball players were found as $\quad 12.84 \pm 1.83$ seconds, rhythm ability means as $2.46 \pm 1.22$ seconds and differentiation ability mean as $9.72 \pm 3.32$ scores. On the other hand, the orientation ability means of handball players were determined as $11.2 \pm 1.11$ seconds, rhythm ability means as $3.23 \pm 1.26$ seconds and differentiation ability mean as $9.55 \pm 2.77$ scores (Lohchab, 2014).

According to the results of a research conducted for the purpose of determining the role of the coordinative abilities in racket sports; orientation ability means of badminton players whose age is in range of 18-25 are 7.54 \pm 6.60 seconds, rhythm ability means are $6.61 \pm 0.52$ seconds and differentiation ability means are $10.10 \pm 2.65$ scores. On the other hand, orientation ability means of table tennis players who are in the same age category are $11.61 \pm 1.56$ seconds, rhythm ability means are $11.12 \pm 1.47$ seconds and differentiation ability means are 7.00 \pm 1.41 scores (Rana and Rajpoot, 2013).

Peker et al., (2018) conducted a study for the purpose of examining the effect of exercise on the coordinative abilities. In the research conducted, football player children whose age is in range of 11-12 were divided into two groups as test and control group. When the pre-exercise pre-test results are examined; the orientation ability means of the test group were found as $8.47 \pm 0.77$ seconds, rhythm ability means as $1.46 \pm 0.26$ seconds and differentiation ability means as $8.75 \pm 3.76$ scores, respectively. The orientation ability means of the control group were determined as $10.80 \pm 0.75$ seconds, rhythm ability means as $1.67 \pm 0.28$ seconds and differentiation ability mean as $8.67 \pm 3.33$ scores, respectively.

In a study carried out, while a significant relation was found between the match ability and balance ability of judoka, no significant relation was found between the rhythm, orientation, differentiation and reaction abilities and match ability. On the other hand, while a significant relation was found between the match ability and balance and differentiation ability of wrestlers, no significant relation was found between the reaction, rhythm and orientation abilities and match ability (Rana and Rajpoot, 2015).

Peker et al., (2017) could not find a significant relation between the balance ability and agility ability of judoka children in a study they conducted.

In conclusion, the findings of the study do not confirm our pre-research expectations. that our pre-research expectations were not confirmed can results from that mean weight of wrestlers was less than judokas' mean weight so rhythm and orientation tests was applied by running and body weight can influence scores of these tests. Once the related literature is examined, it is seen that there are many various results related with the coordinative abilities pertaining to different sports branches. Thus, it may be recommended to conduct a norm study which presents the level which coordinative abilities that are specific to the wrestling and judo branches should be, following the study to be carried out with a broader sampling group.

\section{References}

Chib, S. S. (2000). Relationship of Selected Psychomotor Variables and Coordinative Abilities to Playing Ability in Volleyball. India, Lakshmibai National Institute of Physical Education Deemed Universty Degree of Doctor of Philosophy in Physical Education, 41-45.

Connick, M., Beckman, E., Spathis, J., Deuble, R., \& Tweedy, S. M. (2015). How much do range of movement and coordination affect Paralympic sprint performance?. Medicine and science in sports and exercise, 47(10), 2216-2223. https://doi.org/10.1249/MSS.0000000000000643

Degoutte, F., Jouanel, P., \& Filaire, E. (2003). Energy demands during a judo match and recovery. British journal of sports medicine, 37(3), 245-249. https://doi.org/10.1136/bjsm.37.3.245

García-Pallarés, J., López-Gullón, J. M., Muriel, X., Díaz, A., \& Izquierdo, M. (2011). Physical fitness factors to predict male Olympic wrestling performance. European journal of applied physiology, 111(8), 1747-1758. https://doi.org/10.1007/s00421-010-1809-8

Holmann, W., \& Hettinger, T. (1980). Arbeits and Training Sgrundlagen. Stutgart, Wiley-VCH, 167-177.

Horswill, C. A. (1992). Applied physiology of amateur wrestling. Sports Medicine, 14(2), 114-143. https://doi.org/10.2165/00007256-199214020-00004 
Horswill, C. A., Scott, J. R., \& Galea, P. (1989). Comparison of maximum aerobic power, maximum anaerobic power, and skinfold thickness of elite and nonelite child wrestlers. International Journal of Sports Medicine, 10(03), 165-168. https://doi.org/10.1055/s-2007-1024894

Hübner-Wozniak, E., Kosmol, A., Lutoslawska, G., \& Bem, E. Z. (2004). Anaerobic performance of arms and legs in male and female free style wrestlers. Journal of science and medicine in sport, 7(4), 473-480. https://doi.org/10.1016/S1440-2440(04)80266-4

Jacini, W. F., Cannonieri, G. C., Fernandes, P. T., Bonilha, L., Cendes, F., \& Li, L. M. (2009). Can exercise shape your brain? Cortical differences associated with judo practice. Journal of Science and Medicine in Sport, 12(6), 688-690. https://doi.org/10.1016/j.jsams.2008.11.004

Kraemer, W. J., Fry, A. C., Rubin, M. R., Triplett-McBride, T., Gordon, S. E., Koziris, L. P., ... Fleck, S. J. (2001). Physiological and performance responses to tournament wrestling. Medicine and science in sports and exercise, 33(8), 1367-1378. https://doi.org/10.1097/00005768-200108000-00019

Lohchab, P. (2014). A comparison of Coordinative ability between volleyball and handball male players, http//:www.bhartiyashodh.com e-journal, 5(3), 28-35.

Minz, A. K. (2003). Relationship of Coordinative Abilities to Performance in Badminton. İndia, Lakshmibai National Institute of Physical Education Deemed Universty Degree of Master of Physical Education, 1-91.

Peker, A. T., \& Vural, M. (2018). The relationship between orientation and rhythm ability of children doing karate. Educational Research and Reviews, 13(23), 764-768. https://doi.org/10.5897/ERR2018.3641

Peker, A. T., Kaya, E., \& Zengin, S. (2017). Examination Of Relationship Between Agility And Balance Performance Of Child Judokas. Journal of International Sport Sciences, 3:1

Peker, A. T., Taskin, H., \& Taskin M. (2018). The Effect of Life Kinetic Trainings on Coordinative Abilities, Journal of International Multidisciplinary Academic Researches, 5(3), 59-71.

Rana, M. S., \& Rajpoot, Y. S. (2013). Impact and role of selected coordinative abilities in racket sports, IJSR International journal of science and research, 4(3), 66-69.

Rana, M. S., \& Rajpoot, Y. S. (2015). Relationship of coordinative abilities to playing in combative sports, IOSR Journal of Sports and Physical Education, 2(2), 01-04.

Runciman, P., \& Derman, W. (2018). Athletes with brain injury: pathophysiologic and medical challenges. Physical Medicine and Rehabilitation Clinics, 29(2), 267-281. https://doi.org/10.1016/j.pmr.2018.01.004

Schlaffke, L., Lissek, S., Lenz, M., Brüne, M., Juckel, G., Hinrichs, T., ... Schmidt-Wilcke, T. (2014). Sports and brain morphology-a voxel-based morphometry study with endurance athletes and martial artists. Neuroscience, 259, 35-42. https://doi.org/10.1016/j.neuroscience.2013.11.046

Singh, H., \& Saini, A. (2017). Relationship of coordinative ability with the skills of basketball. International Journal of Yoga, Physiotheraphy and Physical Education, 2(3), 56-59.

Singh, K. (2004). Comparision of Selected Coordinative Abilities Among Sportsmen Belonging to Contact, Semi-Contact and Non-Contact Sports. İndia, Lakshmibai National Institute of Physical Education Deemed Universty Degree of Doctor of Philosophy in Physical Education, 22-35.

Smidu, N. (2014). The importance of Coordinative Abilities in Achieving Athletic Performance. Marathon, 6(1), 91-95.

Taskin, M., Peker, A. T., Taskin, H., \& Ünveren, A. (2017). The relationship between agility and orientation ability in judoka children. Turkish Journal of Sport and Exercise, 19(3), 350-353. https://doi.org/10.15314/tsed.368004

Van Malderen, K., Jacobs, C., Ramon, K., Evert, Z., Deriemaeker, P., \& Clarys, P. (2006, July). Time and technique analysis of a judo fight: a comparison between males and females. In Annals of the 11th Annual Congress of the European College of Sport Science.

\section{Copyrights}

Copyright for this article is retained by the author(s), with first publication rights granted to the journal.

This is an open-access article distributed under the terms and conditions of the Creative Commons Attribution license which permits unrestricted use, distribution, and reproduction in any medium, provided the original work is properly cited. 